\title{
10 Production Technology of Commercial Terrestrial Orchids for Cut Flowers
}

\subsection{Introduction}

Terrestrial orchids grow on the ground level in the soil. Most of these can be found in North America, Europe, and cooler regions of Asia. There are a great number of species even among the terrestrial orchids. They are either found on the forest floor under shade (for example Calanthe, Acanthephippium, Eulophia macrostachya, Tainia, Phaius etc.) or in open grasslands and meadows like Habenaria, Peristylus, Pachystoma, Ipsea, Eulophia nuda etc. These orchids are rich in starch and alkaloids and medicinally important.

Based upon growth habit, terrestrial orchids are either creeping or erect type and can be divided into two types: the solitary type and those growing in clumps or tufts. Within the solitary type group of terrestrial orchids there are two kinds of growth habit; one with plants producing single, erect, leafy stems arising from underground tubers or corms which are terminated by an inflorescence. They are deciduous after fruiting and seeding are completed. The tubers or corms continue their life cycle after completion of an annual period of dormancy. Orchids with the second type of solitary growth habit produce a flowering shoot and leafy shoot from separate buds on the rhizome. Genera such as Nervilia, Eulophia and Pachystoma are examples of this type. The erect terrestrials are usually evergreen, retaining their leaves for more than a year. Each new growth starts from the base of the leafy pseudobulbs as in the genera Liparis, Acanthephippium, Calanthe and Phaius.

The creeping terrestrial orchids have mostly slender, smooth, fleshy rhizomes with elongated internodes and several short or long roots at the nodes. Axillary buds, formed below the apex of the rhizomes produce and ascending leafy and flowering shoot. New annual growth is repeated at the end of flowering, fruiting and, in most cases, after leaf fall. The mother ascending shoot gradually becomes prostrate and becomes an additional part of the rhizome. Examples of orchid genera in New Guinea with this type of growth habit are Erythrodes, Eurycentrum, Eucosia, Hetaeria, Macodes, Vrydragzynea and Zeuxine.

Terrestrial orchids generally prefer:

- A potting medium that retains moisture

- Even watering

- Moderate humidity

- Less air movement

- Less fertilizer

- Cooler temperatures

- Lower light levels

(cc)BY-NC-ND $\odot 2014$ Lakshman Chandra De, Promila Pathak, A.N. Rao, P.K. Rajeevan This work is licensed under the Creative Commons Attribution-NonCommercial-NoDerivs 3.0 License. 


\subsection{Calanthe}

Calanthe is a genus of about 200 terrestrial species that are widespread throughout all tropical areas but are highly concentrated in Asia. The first man-made orchid hybrid created was a Calanthe Dominii, back in 1853, and Calanthe were very popular hothouse plants during the Victorian Era.

There are two types of Calanthe, the deciduous ones which generally have large, silvery pseudobulbs, drop their leaves in winter, and require less water during winter; and the evergreen Calanthe which have either no pseudobulbs or very inconspicuous ones, usually keep their leaves for several seasons, and require even moisture year round. The scape is axillary, terminal or lateral from a leafy pseudobulb. The racemes are long, bearing few to 20 flowers, which are subtended by leafy bracts. The flowers are basically white, red or mauve, medium sized and attractive.

\subsubsection{Genetic Resources (De, 2011)}

Calanthe triplicata: This species is native to the Philippines, Pacific Islands and Australia. An evergreen species with hairy long inflorescence. The flowers are white coloured with reddish and yellow tinge turning black with age and produced during summer and autumn.

Calanthe masuca: An evergreen species of Sikkim Himalaya and Western Ghat with elliptic-ovate to lanceolate leaves. Inflorescence is $90 \mathrm{~cm}$ tall and crowded with 12 to 15 small blue violet flowers.

Calanthe Regnieri: A deciduous species from Vietnam. The inflorescence is $45 \mathrm{~cm}$ long, pubescent with 8-10 flowers. The flowers are white tinged with pink and produced during winter season.

Calanthe rosea: A deciduous species from Burma. The pseudobulbs are spindle shaped. The leaves are broadly lanceolate. The inflorescence is raceme and many flowered. The flowers are long lasting and rose pink to white or dark rose in colour and produced in autumn and winter.

Calanthe veratrifolia: This species is native to India and Australia. The leaves are elliptic and distinctly folded light green in colour. The inflorescence is $150 \mathrm{~cm}$ tall, erect and many flowered. The flowers are long lasting, white and produced during May.

Calanthe vestita: A deciduous species from India, Malay Peninsula, Burma and Thailand. The pseudobulbs are conical, egg shaped carrying 3-4 leaves. The inflorescence is $150 \mathrm{~cm}$ tall, arching and arranged with large white flowers.

Calanthe veitchii: It is a hybrid of Calanthe rosea and Calanthe vestita. The pseudobulbs are elongated with deciduous leaves. The inflorescence is $75 \mathrm{~cm}$ tall with rich rose flowers. The flowers are long lasting and suitable as cut flower and produced in January -February. 
Calanthe sylvatica: A terrestrial tropical and subtropical orchid from North East India. Flowers are large lilac to deep purple with a prominent spur and produced in August-September.

Calanthe alasmifiolia: Native to Bhutan, India, Sikkim, West Bengal, Arunachal Pradesh and Nepal. The inflorescence is corymb. The flowers are white and produced in May-June.

Calanthe biloba: Native to Bhutan, India and Nepal. Pseudobulbs are elongated. The flowers are yellow-ochre spotted with violet or purple brown and produced in September-November.

Calanthe brevicornu: Native to Bhutan, India and Nepal. Pseudobulbs are round. The inflorescence is terminal and arranged with 8 to 15 flowers. Flowers are brick red to purple red colour striped with white or yellow and produced in May-June.

Calanthe chlorleuca: Native to Bhutan and India. Pseudobulbs are conical cylindric. The flowers are yellow green, fragrant and produced in April-May.

Calanthe puberula: Native to India, Bhutan and Nepal. The pseudobulbs are ovoid-conical. The flowers are loosely arranged with inflorescence. The flowers are pale-lavender and produced in June to August.

Calanthe discolor: An evergreen species. Flowers are pure white.

Calanthe aristulifera: A rarest endemic species of Japan. An evergreen species, $45 \mathrm{~cm}$ tall spikes bearing light pink flowers.

\subsubsection{Hybrids}

During the 1850's, Mr. Dominy developed first hybrid, Calanthe dominyi, which is a cross bettwen Calanthe masuca and Calanthe furcata.

\subsubsection{Inter-specific Hybrids}

Hizen $=$ Calanthe discolor $x$ Calanthe aristulifera

Ghita Norby $=$ Calanthe triplicata $x$ Calanthe madagascariensis

Egg Drop $=$ Calanthe arisamensis $x$ Calanthe striata

Tydares Sieboca $=$ Calanthe striata $\times$ Calanthe masuca

Calanthe Sieboldii ‘Takane' hybrids, Calanthe Kozu 'Spice' hybrids

\subsubsection{Bigeneric Hybrids}

Phaiocalanthe $=$ Phaius $x$ Calanthe

Gastrocalanthe $=$ Gastrorchis $x$ Calanthe 


\subsubsection{Inter-varietal Hybrids}

'Elegance', 'Tsiku Flamingo', 'Tsiku Honolulu', 'Narita', 'Urayasu', 'Pink Champagne’, 'Mont Nicholle', 'Kitayama', 'Koriyama', 'Ranyu', 'Bouvet', ‘Mac’s Gold’, 'Mont Isaac', 'Mont Couchon', 'Mont Remon'.

\subsubsection{Uses}

These species are used as cut flowers. Calanthe orchids are rich in linalool, methyl benzoate, methyl salicylate, carvone and cinnamic aldehyde. Calanthe masuca is used for the treatment of acnes and inflammatory sebaceous cysts.

\subsubsection{Cultivation}

Basically they grow terrestrially in deep patches of forest humus, on rotting logs, and among rocks with crevices filled with leaf litter. In cultivation one should practice in pots in order to get the best growth and blooming from the plants. The plants grow well in a temperature range of $15-25^{\circ} \mathrm{C}$, light intensity of $1800-2500$ foot candles and relative humidity of $50-70 \%$. They require ventilated, well lighted and airy conditions for proper growth and flowering. The compost mixture should consist of charcoal, tree bark, sphagnum moss, pea nut shells, cow dung, perlite and sandy soil. Dilute liquid manure is to be applied at monthly intervals. Propagated by the division of bulbs.

\subsection{Eulophia}

Eulophia consists of 300 species of sympodial terrestrial orchids from Africa, Madagascar, Malayasia, Sri Lanka, China, America and India. The pseudobulbs are subterranean topped by 3 to 5 linear-lanceolate leaves. The leaves are leathery or soft, $1.8 \mathrm{~m}$ tall and 10-12.5 $\mathrm{cm}$ wide. The inflorescence is simple or branched and bears few to many attractive flowers which are long lasting. The flower spikes are 1-2 $\mathrm{m}$ tall and arranged with diverse types of flowers, which are yellowish or greenish in colour with some brown and purplish markings.

\subsubsection{Genetic Resources}

Eulophia alata: Native to South Florida, Brazil and West Indies. The pseudobulbs are corm like, subterranean and borne in a long creeping series and $7.5 \mathrm{~cm}$ across. Leaves are dark green and arise from pseudobulbs, $1.2 \mathrm{~m}$ tall and $7.5 \mathrm{~cm}$ across. The inflorescence is $1.5 \mathrm{~m}$ tall, raceme, and bearing attractive flowers. The flowers are $4 \mathrm{~cm}$ in 
diameter, scented, long lasting, greenish bronze yellow or dull yellow, green purple or maroon in colour with cup shaped maroon purple lip and produced in autumn and winter.

Eulophia andamanensis: Native to Andaman Islands. The stems are tuberous at base. Eulophia ovalis: Native to tropical Africa. Plants are $70 \mathrm{~cm}$ tall with purple and white or cream to lilac in colour.

Eulophia explanata: A tall robust species from Garhwal, Kerala, Chhotanagpur and Kumaon with a short pseudostem covered by sheathing bases. The inflorescence is $60 \mathrm{~cm}$ tall with lemon yellow flowers. The flowers are produced during June-July.

Eulophia guineensis: Native to West tropical Africa. The pseudobulbs are clustered, furrowed, and irregular with stalked narrowly elliptic leaves. The inflorescence is raceme like, erect, $90 \mathrm{~cm}$ tall and has 10-15 flowers. The flowers are fragrant, long lasting, waxy, greenish brown with a white lip.

Eulophia mackinnonil: A tropical and subtropical species from Western Himalayas. Pseudobulbs are flat, triangular with acuminate and lanceolate leaves. The inflorescence is a raceme and 8 to 12 flowered. The flowers are yellow to reddish brown and produced in July-August.

Eulophia spectabilis: A terrestrial species from Bhutan, India and Nepal. Pseudobulbs are spherical and subterranean with 3 to 4 pleated leaves. The inflorescence is 5-15 flowered. Flowers are purple brown to pure green in colour and produced in April-July. Eulophia nuda: A tuberous plant with smooth spherical leaves. Leaves are elliptic. Flowers are lax-raceme, 9-20 flowered and rose-pink in colour.

Eulophia parviflora: Native to Eastern Cape and grown in grassland and rocky slopes. Flowers are pleasantly scented with brown and yellow flowers.

Eulophia aculeata: Native to southwestern Cape to Mpumalanga. Plants are rhizomatous, $50 \mathrm{~cm}$ tall with ivory to greenish, pink or purple flowers.

Eulophia clavicornis: Native to tropical Africa. Plants are rhizomatous, $80 \mathrm{~cm}$ tall with white to purple or yellow petals.

Eulophia foliosa: Native to South Africa. Plants are $60 \mathrm{~cm}$ tall with dense elongated clusters of lime green flowers.

\subsubsection{Hybrids}

Eulophia x burundiensis (Eulophia cucullata x Eulophia flavopurpurea), an inter-specific hybrid is native to South Africa. Flowers are large and bright yellow in colour. Popular as pot plants. Another hybrid available in this genera is 'John Davison'.

\subsubsection{Medicinal Eulophia}

Tubers of Eulophia ochreata are used for the treatment of earache and toothache. In India, the tubers of Eulophia nuda are used to treat tumours, scrofulous glands, 
blood disorders, bronchitis, tuberculosis and as a vermifuge. Raw tubers are eaten in rheumoid arthritis. Eulophia speciosa, a native to Africa is used as food sources, for medicinal purposes and in superstition. The attractive flowers are used on letter stamps.

\subsubsection{Cultivation}

Eulophias prefer humid and well lighted location, exposure to direct sun should be avoided. The sympodial terrestrial species prefer a temperature range of 10 to $15^{\circ} \mathrm{C}$, relative humidity of 40-60\% and light intensity of 3000-5000 foot candles depending upon the species. The pot mixture comprising of leaf mould, sandy soil, tree bark, sphagnum moss and perlite mixture is good. Application of dilute liquid form of well rotted cowdung manure at monthly intervals is beneficial. Epiphytic species should be grown on osmunda fibre or tree fern block with sphagnum moss.

\subsection{Phaius}

Phaius consists of 30 species of terrestrial orchids distributed in East Africa to Tropical Asia, Pacific Islands, Himalayas, New Caledonia, Indonesia and Fiji Islands. The pseudobulbs are stocky and thickened and arranged with 2 to 8 large, thin, deeply grooved, long and lance shaped leaves. The individual leaf is $1.2 \mathrm{~m}$ long and $20-25 \mathrm{~cm}$ wide. The inflorescence is 90 to $120 \mathrm{~cm}$ long, arises from the rhizome base between the point of attachment of two leaves. The flowers are large, showy, $10 \mathrm{~cm}$ across, long lasting and of various colours.

\subsubsection{Genetic Resources}

Phaius tankervilliae: Native to tropical Asia, Australia and Pacific Islands. The pseudobulbs are lightly clustered, dull green with very large folded and heavy leaves. Inflorescence is stout longer than leaves, tipped by a spike of 15-20 flowers. The flowers are $11 \mathrm{~cm}$ across, long lasting, sweet smelling. The fragrant flowers are silvery on the outside and have yellowish throats. Commonly known as 'Nun's Orchid'. Flowers are produced during December-March.

Phaius humboltii: Native to Madagascar. The leaves are $50 \mathrm{~cm}$ long and broadly lanceolate. Inflorescence is 15 to 20 flowered, erect and thick. The flowers are $6.5 \mathrm{~cm}$ across and rose coloured. Flowers are produced during June-July.

Phaius flavus: Flowers are $45 \mathrm{~cm}$ tall and are usually produced during April-June. The species is native to Japan and Asia. Commonly known as 'Rock Orchid'. Flowers are yellow with a reddish brown banded lip. Pseudobulbs are conical, topped with 50-60 cm long plicate variegated leaves. 


\subsubsection{Commercial Hybrids}

'Masako', 'Morningstar', 'Spring Fever’

\subsubsection{Herbal Medicines}

Paste of pseudobulbs of Phaius tankervilliae is used to heal swellings of hand and legs, and in poultices to soothe pain of abscess.

\subsubsection{Cultivation}

Phaius should be grown in a temperature range of $16^{\circ} \mathrm{C}$ to $24^{\circ} \mathrm{C}$ night to day. However, the plants will tolerate lower temperatures to $10^{\circ} \mathrm{C}$ or higher to $32^{\circ} \mathrm{C}$. They enjoy bright light or light shade. Plants are grown in pots with a mixture of 2 parts coarse peat moss, 2 part sandy loam and 1 part each perlite and fine bark and watering with good drainage. Fertilize the plants at every third watering with a balanced Orchid fertilizer, such as 18-18-18, diluted to half the strength recommended. Repotting of phaius orchids is required every two or three years. They are propagated by flower stalk cuttings or divisions.

\subsection{Pleione}

Pleione consists of 20 species of cool growing terrestrial or lithophytic orchids distributed in China, Formosa, the Himalayas and South East Asia. These deciduous orchids are known as 'Indian Crocus'. The psedubulbs are angular, one clustered, small and sometimes mottled with black. These pseudobulbs are topped by a solitary folded leaf. Pseudobulbs arise from the base of each pseudobulb, one or two flowered and attractive. The flowers are delicate and frilled.

\subsubsection{Genetic Resources}

Pleione humilis: This species is native to Sikkim and grown in high altitude. The pseudobulbs are egg shaped and clustered with solitary, folded and deciduous leaves. The flowers are $12.5 \mathrm{~cm}$ across, fragrant, white and produced during September-October.

Pleione maculata: A dwarf orchid from India. The pseudobulbs are flask shaped or almost conical, compressed and tuberculate at base. The leaves are folded, two and deciduous. The flowers are solitary, fragrant, $5 \mathrm{~cm}$ across, long lasting, white and produced during October-November. 
Pleione praecox: Distributed in South China, India, Burma and Himalayas. The pseudobulbs are egg shaped, lightly clustered, bottle shaped and depressed at the apex. The leaves are 2, folded, deciduos and elliptic to lanceolate. The flowers are solitary, fragrant, long lasting, $12.5 \mathrm{~cm}$ across, magenta red in colour and produced during December.

\subsubsection{Hybrids}

\subsubsection{Inter-specific Hybrids}

'Io', 'Mandrill', 'Gelada', 'Kima', 'Langur', 'Polto', 'Dr. Mo Weatherhead', 'Bonobo', 'Mariemonda', 'Lucey', 'Muriel', 'Orangutan', 'Nozomi', 'Spring', 'Renate', 'Lilac Wonder', 'Umpqua Jan Shan', 'Yeti’, ‘Zottel’, ‘Sinope’, ‘Kyoto’, ‘Confirmation’.

\subsubsection{Inter-varietal Hybrids}

'Darwin', 'Gorilla', 'Wahakari', 'Jake Butterfield', Helen Brownsword', 'Vicky', 'Michael Butterfield', 'Snow Monkey’, 'Adabra', 'St. Helens', 'Badaling', 'Fan Jiang', 'Kiku’, 'Mikado', ‘Trask', 'Ashmore’, ‘Calypso', 'Titan’.

\subsubsection{Variety - species Hybrids}

'Aye-Aye', ‘Austice Harris', 'Sifaca', ‘Tai Pan', ‘Kong', 'Mardin', ‘Leda', ‘Bo Pan', Little Goose Pagoda', 'Yokata', 'Sakura’, Floor Shan', Hazlebury’.

\subsubsection{Medicinal Pleione}

Pseudobulbs of Pleione maculata are used in liver complaints and stomachache. Pseudobulbs of Pleione formosana are rich in dihydrophenanthrene, pleioanthrenin, bibenzyls, pleiobibenzynin and cyclomargenyl -p-coumarate. The pseudobulbs are used to treat tumors.

\subsubsection{Cultivation}

Pleiones prefer bright filtered light with the intensity of 1000-1500 foot candles. Most Pleiones require cool to intermediate temperatures. Maximum day temperatures should be between $22-25^{\circ} \mathrm{C}$, and night minimums between $15-18^{\circ} \mathrm{C}$. During the winter months, the plants benefit from a night minimum between $10-15^{\circ} \mathrm{C}$.

Plants are grown in shallow clay pots or pans. The potting mixture should consist of tree bark, peat and sphagnum moss. Plenty of fresh air movement and watering are essential. Plants are propagated by divisions of bulbs. 